\section{JURVAL PHASPATIIII}

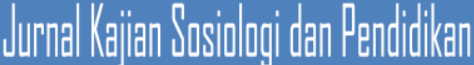

Jurnal Perspektif: Jurnal Kajian Sosiologi dan Pendidikan

Vol. 1 No. 4 Tahun 2018

http://perspektif.ppj.unp.ac.id

Email: perspektif@ppj.unp.ac.id

ISSN: 2622-1748 (Online), 2684-902X (Print)

DOI: $\underline{\text { http://dx.doi.org/10.24036/perspektif.v1i4.56 }}$

\title{
Strategi Adaptasi Mahasiswa UNP Non Muslim dalam Kegiatan Praktek Kependidikan (PLK) Pada Sekolah Praktek Lapangan di Kota Padang
}

\author{
Fransisca Margareta Wende ${ }^{1}$, Erianjoni Erianjoni ${ }^{2}$, Desri Nora $^{3}$ \\ 1,2,3 Universitas Negeri Padang \\ email: fmargareth025@gmail.com
}

\begin{abstract}
Abstrak
Penelitian ini dilatarbelakangi oleh ketertarikan peneliti melihat mahasiswa UNP PLK non Muslim menjalankan Program Praktek Lapangan Kependidikan (PPLK) selama empat bulan di sekolah. Tujuan penelitian ini untuk mengetahui Strategi Adaptasi Mahasiswa non Muslim dalam kegiatan Praktek Lapangan Kependidikan pada sekolah di Kota Padang. Hasil temuan dianalisis dengan teori Struktural Fungsiona oleh Talcott Parsons. Penelitian ini menggunakan pendekatan kualitatif dengan tipe penelitian studi kasus. Hasil penelitian ini mengungkapkan yang menjadi strategi adaptasi mahasiswa UNP PLK non Muslim dalam kegiatan Praktek Lapangan Kependidikan adalah; (1) adaptasi berpakaian muslimah menggunakan jilbab, (2) adaptasi dengan lingkungan sekolah,(3) adaptasi dengan kegiatan sekolah
\end{abstract}

Kata Kunci: Mahasiswa PLK non Muslim, Adaptasi, Strategi

\begin{abstract}
The background of this study was the interest of researcher to examine non-Muslim UNP PLK students during the four months of the Education Field Pratice Program (PPPLK) at schools. The purpose of this studywas to determine the Adaptation Strategy of non-Muslim UNP students in Educational Field Pratice activities at schools in Padang city. The findings were analyzed by using the theory of Functional Structures proposed by Talcott Parsons. This study used a qualitative approach as the type was case study research. The results of this study revealed that the adaptation strategy of nonMuslim UNP PLK students in the Educational Field Pratice activities were:(1) adaptation to Muslim clothing using hijab, (2) adaptation to the school environment and (3) adaptation to the school activities
\end{abstract} Key Word: Non-Muslim PLK students, Adaptation, Strategy 


\section{Pendahuluan}

Universitas Negeri Padang sebagai lembaga pendidikan yang membuka jalur program kependidikan, dan mencetak guru yang berkompeten. Untuk meningkatkan mutu dari para lulusannya maka Universitas Negeri Padang memberikan suatu program yang memberikan mata kuliah yang bersifat praktik dan khusus yang dinamakan Program Pengalaman Lapangan Kependidikan (PPLK). PPLK merupakan suatu program pendidikan dalam penjabatan guru yang dirancang khusus untuk menyiapkan para calon guru agar mampu untuk menguasai kompetensi keguruan yang utuh dan terintegrasi sehingga pada saat terjun langsung ke dunia pendidikan dan menjadi guru yang sesunguhnya mereka siap untuk mengemban tugas dan tanggung jawab seorang tenaga pendidik. ${ }^{1}$

Mahasiswa UNP PLK non Muslim yang menjalankan praktek lapangan kependidikan di sekolah, menjalin interaksi dengan teman mahasiswa UNP dari bermacam fakultas melalui berbagai aktifitas bersama seperti mengerjakan piket di ruang wakil kepala sekolah, mengerjakan piket di ruang perpustakaan dan mengerjakan piket di ruang tata usaha. Dengan menjalankan adaptasi dalam hubungan pertemanan dengan teman PLK, maka mereka akan diterima dengan baik di dalam kelompoknya. Kelompok dalam sekolah mitra yaitu kelompok teman mahasiswa PLK dari perguruan tinggi di Kota Padang.

Universitas Negeri Padang dalam kegiatan praktek lapangan kependidikan, bekerjasama dengan sekolah mitra yaitu sekolah negeri. Sekolah mempunyai kultur yang bisa diamati seperti: arsitektur, tata ruang, eksterior dan interior, kebiasaan dan rutinitas, peraturan-peraturan, ceritacerita, upacara-upacara, ritus-ritus, simbol, logo, slogan, bendera, gambar-gambar, tanda-tanda, sopan santun dan cara berpakaian. ${ }^{2}$ Penyesuaian diri yang dihadapi mahasiswa PLK non Muslim di sekolah praktek lapangan kependidikan yaitu situasi baru atau lingkungan baru di sekolah.

Penelitian ini dianalisis dengan menggunakan skema AGIL yang dikemukakan oleh Talcott Parsons dimana strategi adaptasi mahasiswa PLK non Muslim

\section{Metode Penelitian}

Lokasi penelitian mengenai strategi adaptasi mahasiswa UNP PLK non Muslim melakukan penelitian di beberapa tempat sekolah mitra SMP Negeri 14 Padang, SMP Negeri 28 Padang, SMA Negeri 14 Padang, SMK Negeri 7 Padang dan SMA YAPI Padang. Alasan pemilihan lokasi penelitian ini adalah karena kelima sekolah tersebut ada mahasiswa PLK non Muslim yang menjalankan praktek lapangan kependidikan di Kota Padang. Penelitian ini dilakukan mulai 16 Agustus 2018-16 September 2018.

Dilihat endekatannya, penelitian ini termasuk kualitatif dengan tipe studi kasus. Pemilihan informan dilakukan secara purposive sampling dengan jumlah informan 31 orang. Data dikumpulkan melalui wawancara, observasi, dan studi dokumentasi. Agar data yang diperoleh bisa dipercaya, maka dalam penelitian ini dilakukan triangulasi data. Kemudian data yang diperoleh dianalisis dengan menggunakan analisis interaktif oleh Milles dan Huberman dengan langkah mengumpulkan data, reduksi data, display data, dan menarik kesimpulan/verifikasi. Dimana aktivitas dalam analisis data ini, dilakukan secara terus menerus pada setiap tahap penelitian sampai penelitian ini selesai.

\footnotetext{
${ }^{1}$ Buku peraturan akademik. 2013. Padang: Universitas Negeri Padang

2 Jurnal Guru, No. 2 Vol 7 Desember 2010. Pengembangan Kultur Sekolah Sebagai Upaya Meningkatkan Mutu Sekolah. Diakses tanggal 10 September 2018 pukul : 12:33 WIB
} 


\section{Strategi Adaptasi Mahasiswa PLK Non Muslim di Tempat Sekolah Praktek Lapangan Kependidikan}

Adaptasi merupakan proses penyesuaian dari individu, kelompok, maupun unit sosial terhadap norma-norma, proses perubahan, ataupun suatu kondisi yang diciptakan. ${ }^{3}$ Adaptasi berjalan dengan baik apabila pelakunya menyesuaikan diri dengan lingkungannya sehingga mampu bergabung tanpa kendala dengan kelompoknya. Sebaliknya, seseorang tidak mampu beradaptasi dengan lingkungan sekitar, maka individu merasa sebagai orang yang terasing, tidak diterima dan dikucilkan di lingkungannya serta ketika menghadapi masalah, individu cenderung mendapatkan bantuan dari lingkungan sosialnya. Manusia diciptakan selain sebagai makluk individu juga sebagai makluk sosial. Oleh karena itu melalui adaptasi yang baik seseorang bisa mencapai tujuan yang diinginkan. Manusia yang memiliki tujuan yang ingin dicapai harus melalui usaha-usaha yang harus dilakukan. Sama halnya dengan Mahasiswa PLK non Muslim untuk mencapai tujuan menjadi guru di tempat sekolah praktek lapangan. Mahasiswa PLK non Muslim memakai jilbab. Untuk mencapai tujuan dan menjalani guru di tempat sekolah praktek lapangan, mahasiswa PLK non Muslim beradaptasi dengan berpakakaian muslimah (jilbab) dan beradaptasi dengan lingkungan sekolah. Tempat sekolah praktek lapangan kependidikan yang dijalankan mahasiswa UNP PLK non Muslim yaitu sekolah Negeri.

\section{Cara berpakaian}

Cara berpakaian di tempat sekolah praktek lapangan, mahasiswa PLK non Muslim memakai busana muslimah (jilbab). Jilbab merupakan salah satu simbol ketaatan bagi seorang muslimah terhadap syari'at agama islam. Jilbab dalam Islam dimaknai sebagai pakaian yang menutup seluruh tubuh dari ujung kepala sampai ke ujung kaki. ${ }^{4}$ Cara berpakaian muslimah di sekolah negeri Kota Padang diatur oleh peraturan daerah di Kota Padang,pewajiban jilbab dan busana Islami (bagi orang Islam) dan anjuran memakainya (untuk non Islam) yang diberlakukan lewat Instruksi Walikota Nomor451.422/Binsos-III/2005 tertanggal 7 Maret di Padang. Dengan adanya peraturan daerah, pewajiban jilbab dan busana bagi non Muslim membuat mahasiswa PLK non Muslim yang melakukan praktek lapangan kependidikan di sekolah memakai jilbab selama praktek lapangan kependidikan berlangsung. Memakai jilbab bagi mahasiswa PLK non Muslim menjadi pengalaman pertama. Sehingga mahasiswa PLK non Muslim belajar memakai jilbab dengan orang-orang terdekat dan media sosial

\section{Belajar memakai jilbab dengan Teman PLK}

Mahasiswa PLK non Muslim belajar jilbab dengan teman PLK. Teman PLK merupakan teman dekat, mahasiswa PLK non Muslim yang menjadi teman karib di sekolah. Teman PLK mengajari mahasiswa PLK non Muslim dalam berpakaian muslimah (memakai jilbab)

\footnotetext{
${ }^{3}$ Soerjono Soekanto.2009. Sosiologi Suatu Pengantar. Jakarta: Rajawali Press. Hal 11

4 Yasinta Fauziah Novitasari.2014. Jilbab sebagai gaya hidup ( studi fenemonologi tentang alas an perempuan memakai jilbab dan aktivitas solo hijabers community). Universitas Sebelas Maret, Surabaya,(jurnal.fkip.uns.ac.id/index.php/sosant/article/view/3620 diakes tanggal 24 Oktober 2018)
} 


\section{Belajar memakai jilbab melalui youtube}

Media sosial salah satunya youtube, membantu mahasiswa PLK non Muslim belajar memakai jilbab. Banyaknya gaya jilbab dengan tutorial jilbab di youtube, memudahkan mahasiswa PLK non Muslim belajar jilbab melalui youtube.

\section{Belajar jilbab dengan kakak mualaf}

Salah satu mahasiswa PLK UNES Padang non Muslim yang melakukan praktek lapangan kependidikan di SMA YAPI. Belajar jilbab dengan kakak kandungnya yang sudah mualaf sepuluh bulan yang lalu. Berdasarkan pemaparan hasil wawancara peneliti dengan informan. Adaptasi mahasiswa PLK non Muslim dalam cara berpakaian di sekolah memakai busana muslimah (jilbab). Anjuran pemakaian busana muslimah (jilbab) untuk non Muslim sudah diatur oleh peraturan daerah Kota Padang melalui instruksi walikota Padang, Fauzi Bahar tentang busana Islami dan anjuran memakainya untuk non Muslim. Sehingga kebijakan tersebut, Kepala sekolah dan Wakil kurikulum yang menyarankan mahasiswa PLK non Muslim selama melakukan praktek lapangan di sekolah memakai jilbab. Memakai jilbab bagi mahasiswa PLK non Muslim merupakan pengalaman pertama bagi mereka. Untuk bisa mencapai tujuannya dalam memakai jilbab, mahasiswa PLK non Muslim beradaptasi memakai jilbab dengan belajar memakai jilbab yang dibantu orang-orang terdekat mereka dan media sosial

\section{Cara beradaptasi dengan lingkungan sekolah}

Manusia tidak bisa hidup sendiri, individu satu sama lain saling membutuhkan orang lain. Sama halnya dengan mahasiswa UNP PLK non Muslim di lingkungan baru, mereka membutuhkan orang lain. Mahasiswa PLK non Muslim di lingkungan sekolah bertemu dengan orang-orang yang baru dikenal seperti guru pamong, teman PLK, siswa-siswa. Diperlukan sebuah proses interaksi dengan orang-orang yang baru di lingkungan sekolah baik itu guru pamong, teman PLK, siswa-siswi maupun mahasiswa PLK non Muslim saling mengenal dan saling memahami satu sama lainnya.

\section{Adaptasi Teman PLK}

Mahasiswa PLK non Muslim sebagai individu yang memerlukan teman untuk dalam segala aktivitas disekolah mitra. Kehadiran teman PLK berperan penting dalam aktifitas sekolah yaitu piket bersama di sekolah, makan bersama di kantin sekolah, menjadi teman curhat disekolah. Teman PLK yang ditemui mahasiswa PLK berbeda-beda jurusan, sehingga teman PLK satu sama lain merupakan orang yang baru dikenal. Mahasiswa PLK non Muslim memerlukan adaptasi dengan teman PLK. Adaptasi yang di hadapi mahasiswa PLK non Muslim dengan teman PLK pertamakalinya memperkenalkan diri. Dengan memperkenalkan diri, mahasiswa PLK non Muslim dapat menjalin hubungan pertemanan di sekolah. Namun ada kendala yang dihadapi mahasiswa PLK non Muslim berinteraksi dengan teman PLK karena karakter beberapa mahasiswa PLK non Muslim yang pendiam (introvert) sulit mengenal teman barunya di sekolah

\section{Adaptasi dengan guru pamong}


Guru pamong merupakan guru pembimbing mahasiswa yang melakukan praktek lapangan kependidikan. Mahasiswa PLK didampingi masuk ke kelas, guru pamong duduk dibelakang kelas melihat mahasiswa PLK yang menerangkan pembelajaran. Pada pembelajaran dikelas, guru pamong menilai mahasiswa PLK non Muslim yang menerangkan pembelajaran di kelas, kalau ada kekurangan guru pamong memberikan saran atau masukan agar mahasiswa kedepannya lebih baik dalam proses pembelajaran di kelas. Selama mahasiswa PLK masuk kelas didampingi guru pamong, ini yang dinamakan masa latihan mengajar terbimbing (LMT) terhitung tanggal 23 juli 2018 sampai 11 Agustus 2018. Setelah masa latihan mengajar terbimbing selesai, mahasiswa PLK memasuki masa latihan mengajar mandiri tanggal 13 Agustus 2018, mahasiswa PLK mandiri dikelas tidak didampingi oleh guru pamong dikelas. Adaptasi yang dilakukan mahasiswa PLK non Muslim dengan guru pamong berkenalan dengan guru pamong, dengan berkenalan mahasiswa PLK non Muslim dapat menjalin hubungan yang harmonis. Selain beradaptasi, mahasiswa PLK non Muslim melakukan strategi dengan cara menanyakan tentang pembelajaran di sekolah untuk mendekati guru pamong.

\section{Adaptasi dengan siswa-siswi}

Siswa-siswi bertemu dengan guru muda yatu mahasiswa PLK yang melakukan kegiatan praktek lapangan kependidikan di sekolah. Siswa-siswi senang mendapatkan guru muda, dan menggagap guru muda sebagai kakak diluar sekolah.

\section{Adaptasi dengan kegiatan di sekolah}

Kegiatan internal sekolah yang diikuti mahasiswa PLK non Muslim di tempat praktek lapangan yaitu Kultum. Kultum merupakan kegiatan kerohanian yang dilaksanakan setiap hari Jum'at. Kegiatan kultum diisi dengan acara membaca Al-Quran, mendengarkan ceramah guru, Nasyid (menyanyikan lagu Islami). Kegiatan kultum dihadiri guru-guru, siswa-siswi dan mahasiswa PLK. Biasanya yang bertugas dalam kultum yaitu kelas-kelas yang mendapat giliran sehingga siswa-siswi diberikan kesempatan dalam membawakan kultum dibimbing oleh wali kelas.

\section{Penutup}

Berdasarkan hasil temuan pada bab III, Strategi Adaptasi Mahasiswa UNP non Muslim dalam Kegiatan Praktek Kependidikan (PLK) Pada Sekolah Praktek Lapangan Di Kota Padang ini ada dua, yaitu (1) cara berpakaian muslimah (jilbab), (2) cara beradaptasi lingkungan sekolah (3) Adaptasi dengan kegiatan di sekolah.Ketiga tersebut berkaitan dengan skema AGIL yang dikemukakan oleh Talcott Parsons.

Setelah dilakukannya analisis terhadap hasil wawancara, maka peneliti dapat mengambil kesimpulan bahwa yang menjadi strategi adaptasi mahasiswa UNP PLK non Muslim dalam penelitian ini adalah skema AGIL. Skema AGIL yang terdiri dari Adaptasi, Pencapaian tujuan, Integrasi dan Latensi berkaitan dengan adaptasi berpakaian muslimah (jilbab), adaptasi di lingkungan sekolah dan adaptasi dengan kegiatan sekolah yaitu kultum. Salah satu usaha untuk bertahan (survive), mahasiswa PLK non Muslim menjalankan teori struktural fungsional, skema AGIL dalam adaptasi berpakaian muslimah (jilbab) adaptasi dengan lingkungan sekolah dan adaptasi dengna kegiatan sekolah. Dalam cara berpakaian muslimah (jilbab) yang di jalankan mahasiswa PLK non Muslim usaha komitmen mahasiswa PLK non Muslim selama menjalankan 
praktek lapangan kependidikan memakai jilbab. Cara beradaptasi dengan lingkungan sekolah yang dijalankan mahasiswa PLK non Muslim usaha untuk menjalin hubungan harmonis dan nilai-nilai kebersamaan.

\section{Daftar Pustaka}

(2010). Pengembangan Kultur Sekolah Sebagai Upaya Meningkatkan Mutu Sekolah. Jurnal Guru, No. 2 Vol 7 Diakses tanggal 10 September 2018

Soerjono Soekanto.(2009). Sosiologi Suatu Pengantar. Jakarta: Rajawali Press. Hal 11

Yasinta Fauziah Novitasari. (2014). Jilbab sebagai gaya hidup ( studi fenemonologi tentang alas an perempuan memakai jilbab dan aktivitas solo hijabers community). Universitas Sebelas Maret,Surabaya, (jurnal.fkip.uns.ac.id/index.php/sosant/article/view/3620 diakes tanggal 24 Oktober 2018)

Universitas Negeri Padang. (2013). Buku Peraturan Akademik. Padang: Universitas Negeri Padang 